\title{
Mechanical obstruction of the peritoneal catheter with ovarian fimbriae, case reports
}

\author{
Juraj Jug ${ }^{1 *}$ (D), Ivica Kocman² (i) and Ingrid Prkačin ${ }^{1,2}$ (B)
}

\begin{abstract}
The number of treated patients with peritoneal dialysis accounts for $2.8 \%$ of all kidney replacement therapy methods and constantly decreases. Peritoneal dialysis should be the first choice as the kidney function replacement treatment method in a transplantation waiting period. Besides all other possible infectious and mechanical complications of peritoneal catheter placement and maintenance, mechanical obstruction by ovarian fimbriae is very rare but potentially dangerous. We present four clinical cases (women 32-56 years) of mechanical obstruction of the peritoneal catheter by ovarian fimbriae during 2012-2014 in Clinical Hospital Merkur, Zagreb, Croatia. We use a laparoscopic technique with Čala trocar for peritoneal catheter placement in the right part of the Douglas cavity using a doublecuff Tenckhoff straight catheter. In our cases, all described obstructions were on the right side of the abdominal cavity. Only one patient had a displaced catheter. This problem was described only in a few case reports in which were presented with fluid exchange difficulties or initial vaginal secretion which can be easily mistaken for urinary incontinence. Mechanical complications connected with a peritoneal catheter can be successfully solved with laparoscopy intervention, which includes the ovary fimbriae obstruction.
\end{abstract}

Keywords: Mechanical obstruction, Peritoneal catheter, Ovarian fimbriae, Dialysis

\section{Introduction}

A global prevalence of chronic kidney disease (CKD) counts about $10-13 \%$. The exact data about CKD prevalence and its changes in Croatia do not exist. The number of treated patients with one of the kidney replacement therapy methods in 2014 was 957 patients per million but only $2.8 \%$ took peritoneal dialysis. The number of treated patients with peritoneal dialysis constantly decreases from 2009 [1]. Peritoneal dialysis is related to a higher survival rate after kidney transplantation if it was used in the treatment regime before the procedure [2].

Peritoneal dialysis is a method of kidney function replacement therapy in which the peritoneum is used as a semipermeable membrane. Dialyzing fluid intake and its evacuation are done by the peritoneal catheter. There are

\footnotetext{
*Correspondence: juraj2304@gmail.com

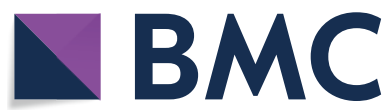

1 School of Medicine, University of Zagreb, Zagreb, Croatia

Full list of author information is available at the end of the article several techniques for catheter placement: percutaneous, fluoroscopic, peritoneoscopic, laparoscopic, and open surgical approaches. Today, the decision of how the catheter will be placed is still made by the surgeon because there is no evidence one of these techniques is superior to the other $[3,4]$.

Complications due to peritoneal catheter placement and maintenance are divided to infectious (infection of the catheter starting point, infection of the catheter tunnel, peritonitis) and mechanical (bowel perforation, bleeding, obstruction by omentum or fibrous tissue, malposition, hernias, dialyzing fluid leaking) $[5,6]$. Also, one of the possible complications is a peritoneal catheter mechanical obstruction by ovarian fimbriae. The aforementioned complication is described in only a few case reports [7-14]. In the treatment of this complication, today salpingectomy, fimbriectomy, or fimbrioplasty are used [11]. (c) The Author(s) 2022. Open Access This article is licensed under a Creative Commons Attribution 4.0 International License, which permits use, sharing, adaptation, distribution and reproduction in any medium or format, as long as you give appropriate credit to the original author(s) and the source, provide a link to the Creative Commons licence, and indicate if changes were made. The images or other third party material in this article are included in the article's Creative Commons licence, unless indicated otherwise in a credit line to the material. If material is not included in the article's Creative Commons licence and your intended use is not permitted by statutory regulation or exceeds the permitted use, you will need to obtain permission directly from the copyright holder. To view a copy of this licence, visit http://creativecommons.org/licenses/by/4.0/. The Creative Commons Public Domain Dedication waiver (http://creativeco mmons.org/publicdomain/zero/1.0/) applies to the data made available in this article, unless otherwise stated in a credit line to the data. 


\section{Case reports}

We present four clinical cases of peritoneal catheter mechanical obstruction by ovarian fimbriae in Clinical Hospital Merkur, Zagreb during 2012-2014. In our Clinic, we use a laparoscopic technique with Čala trocar for peritoneal catheter placement in the right part of the Douglas cavity using a double-cuff Tenckhoff straight catheter. This technique was conceived in 1994 [12].

1. Female 56 years A lavage with saline solution was done after the successful catheter placement with great fluid input and output. The treatment with continuous ambulatory peritoneal dialysis (CAPD) with 4 exchanges with $1.5 \%$ glucose the solution was started 40 days after the procedure. The first difficulties in fluid exchange were noticed 16 days after. The problem was solved with the partial catheter replacement and heparin use in the dialyzing fluid. Unfortunately, a few minutes later there was no fluid exchange. $8 \mathrm{~mL}$ of saline solution combined with $1 \mathrm{~mL}$ heparin was instilled into the catheter with no improvement. One month after these complications, exploratory laparoscopy was done (Fig. 1). Mechanical obstruction of the peritoneal catheter by right ovarian fimbriae was found after which fimbriectomy was done. Peritoneal dialysis was performed during the next six months with no complications. Suddenly, a patient developed acute peritonitis which was successfully treated in the hospital. One year later, the peritoneal catheter was removed due to recidivating peritonitis. AV fistula was formed, and the patient was afterward treated with hemodialysis.

2. Female 34 years, nullipara A peritoneal catheter was placed with no complications. Three days later, there were difficulties in the output of dialyzing fluid. The undetermined catheter obstruction was confirmed by diascopy (Fig. 2). Two weeks after, laparoscopy was

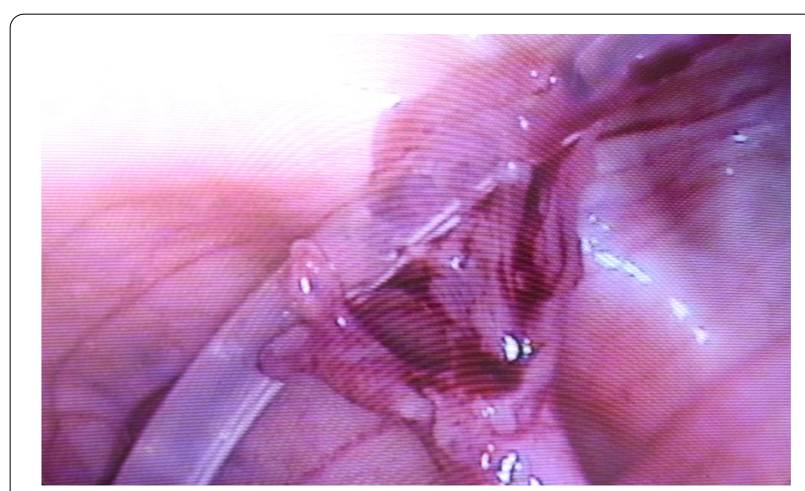

Fig. 1 Mechanical obstruction of peritoneal catheter by right ovarian fimbriae at laparoscopy

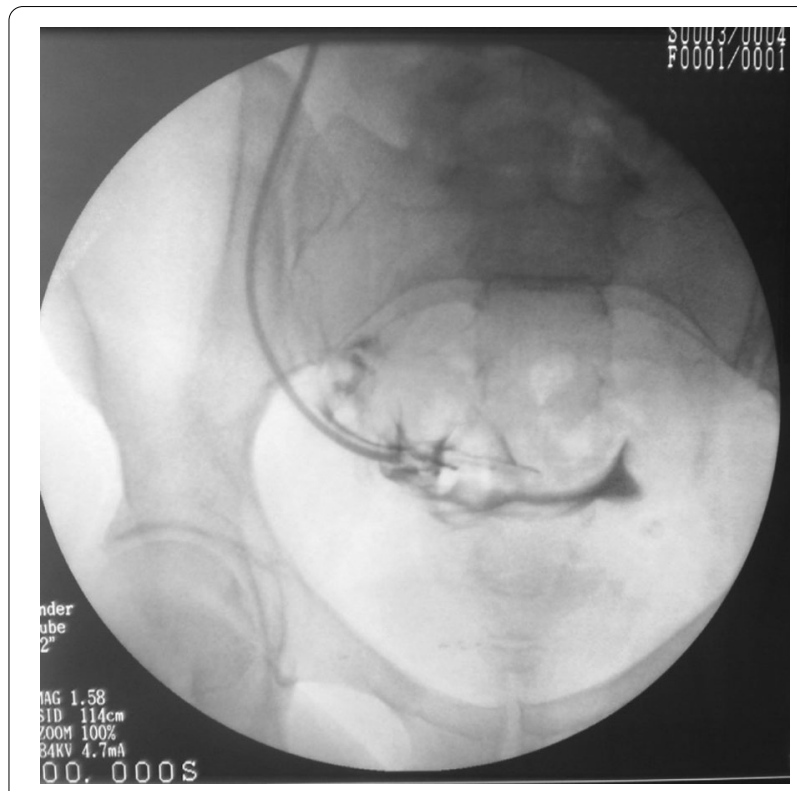

Fig. 2 Diascopy image of obstructed peritoneal catheter by right ovarian fimbriae filled with contrast

performed in which catheter obstruction with right ovarian fimbriae was found. The peritoneal catheter was replaced with no complications afterward. After two months, the peritoneal dialysis fluid exchange was started with a satisfactory fluid exchange. One and a half years later, simultaneous kidney and pancreas transplantation was done with peritoneal catheter removal.

3. Female 44 years A peritoneal catheter was placed with no complications. Two months later, the CAPD procedure was started with 4 exchanges of $1.5 \mathrm{~L}$ fluid with a $1.5 \%$ glucose solution. At the first exchange, there were difficulties with the fluid exchange. The $\mathrm{X}$-ray showed the malposition of the catheter, but the cause was not found on the exploratory laparoscopy procedure. These complications were explained as right ovarian fimbriae leaning on the catheter perforations and the catheter was replaced. One month later the same complications appeared when the other catheter was placed at the left side of the abdominal cavity. Two months after, the patient developed bilateral pretibial edema and heart failure due to inadequate kidney function replacement. Nine months after, simultaneous kidney and pancreas transplantation was performed.

4. Female 32 years After the catheter placement with no complications, in the next nine months, the patient did not indicate starting the CAPD. The CAPD procedure was started because of uremic symptoms with 3 exchanges with $2 \mathrm{~L}$ of $1.5 \%$ glucose solution. Five 
days later, the fluid exchange was blocked. The total mechanical obstruction of the peritoneal catheter by right ovarian fimbriae was confirmed with exploratory laparoscopy. A total right salpingectomy was performed, and a new peritoneal catheter was placed. The postoperative period was remarkable with no further complications in fluid exchange procedures.

\section{Discussion}

As the number of patients on peritoneal dialysis tends to increase, we need to pay attention to mechanical obstruction of the peritoneal catheter by ovarian fimbriae as a rare possible complication. Laparoscopy is a superior method for setting the right diagnosis and catheter obstruction removal with better outcomes. Because there is no discontinuation of the abdominal wall, the peritoneal dialysis can be continued immediately [14-24]. The mechanical obstruction of the peritoneal catheter by ovarian fimbriae was described in only a few case reports in which were presented with fluid exchange difficulties or initial vaginal secretion which can be easily mistaken for urinary incontinence. According to the available data, in nine cases the ovarian fimbriae obstructed the peritoneal catheter placed on the right side of the abdominal cavity, and in five on the left side (Table 1) [7-14, 24-31].
In our cases, all described obstructions were on the right side of the abdominal cavity, and only one patient had a displaced catheter. To save the reproductive function, in younger patients fimbriectomy, catheter fixation or salpingopexy can be performed. In all other patients, the main treatment method is a salpingectomy.

In the literature, the time from catheter placement to the first signs of mechanical obstruction varies from 2 to 5 months due to unknown reasons [9, 10, 14, 24-31]. A list of all cases can be seen in Table 1 . In our patients, that time was 3 days to 9 months, and after the laparoscopic removal of the ovarian fimbriae with one of the suggested methods, there were no repeated complications caused by them [13].

\section{Mini review}

Obstruction of the peritoneal dialysis catheter of all causes occurs in 3-20\% of cases [32]. These cases were associated with omentum wrapping with or without peritonitis, ovarian tube fimbriae blockage, or clotting. Lowering the position of the catheter insertion may reduce the omental wrapping, but there is no data about the obstruction by fallopian tube fimbriae [33]. Although the mechanism of catheter obstruction by fallopian tube fimbriae is still unclear, it is known that these fimbriae contract during ovulation and thus cover the ovaries. Since most cases are found in women of generative age, this

Table 1 Cases of peritoneal catheter obstruction by ovarian fimbriae from the literature and our clinic

\begin{tabular}{|c|c|c|c|c|c|c|}
\hline Age (years) & $\begin{array}{l}\text { Time from placement } \\
\text { to obstruction }\end{array}$ & $\begin{array}{l}\text { Side of the } \\
\text { abdominal cavity }\end{array}$ & $\begin{array}{l}\text { Displacement of } \\
\text { the catheter? }\end{array}$ & Procedure & Successful? & References \\
\hline 39 & ND & Right & No & Laparoscopy & Yes & [7] \\
\hline 51 & 2 months & ND & No & Laparoscopy & Yes & {$[8]$} \\
\hline 56 & 3,5 months & Right & No & Laparoscopic salpingectomy & Yes & {$[10]$} \\
\hline 45 & 2 weeks & Left & No & Laparoscopy & Yes & [11] \\
\hline 49 & 2 months & Left & No & Mini laparotomy & Yes & [14] \\
\hline 65 & 4 months & Right & No & Laparoscopy & Yes & [24] \\
\hline 37 & ND & Right & No & Laparotomy & No & [26] \\
\hline 29 & 3 days & Right & No & Laparotomy & Yes & {$[27]$} \\
\hline 2 & ND & Left & No & Laparoscopic salpingectomy & Yes & {$[28]$} \\
\hline 1.5 & 5 months & Right & No & Laparoscopy & Yes & [29] \\
\hline 62 & 7 days & Left & No & Laparoscopy & Yes & {$[30]$} \\
\hline 32 & 1 month & Left & No & Laparoscopic omentopexy & Yes & [31] \\
\hline 24 & 2 weeks & Right & No & Laparoscopic omentopexy & Yes & {$[31]$} \\
\hline 57 & 2 months & Right & No & Laparoscopy & Yes & [31] \\
\hline 79 & 3 months & Right & No & Laparoscopy & Yes & {$[31]$} \\
\hline 56 & 16 days & Right & No & Laparoscopy & Yes & OWN \\
\hline 34 & 3 days & Right & No & Laparoscopy & Yes & OWN \\
\hline 44 & 2 months & Right & Yes & Laparoscopy & Yes & OWN \\
\hline 32 & 9 months & Right & No & Laparoscopy & Yes & OWN \\
\hline
\end{tabular}

$N D$ no data 
Table 2 Characteristics of minilaparotomy and laparoscopy procedures [13]

\begin{tabular}{lll}
\hline & Minilaparotomy & Laparoscopy \\
\hline Structure display & Direct vision & Video camera \\
Procedure duration & $28-51$ min & $45-75$ min \\
Hospital stay & $2-5$ days & $1-2$ days \\
Peritoneal dialysis resumption & After 2 weeks & Immediately \\
\hline
\end{tabular}

mechanism could play the key role in the pathogenesis of this disease, especially during ovulation. In children, only two cases in 18 month and two-year-old girls have been described [28, 29]. It is also unclear why more of these obstructions occur on the right side. Because of the aforementioned, salpingopexy is the most successful method in releasing the peritoneal catheter from the fimbriae, but in case of repeated obstruction at the generative age, salpingectomy is necessary. The indications for salpingectomy are very strict, and in addition to the previous one, they include only postmenopausal obstruction [9]. Japanese authors Sakurada et al. [13] suggest minilaparotomy as the main method of approach to obstruction, emphasizing its advantages such as showing obstruction under direct vision and shorter operation time. It should be noted that after a minilaparotomy it is necessary to do a pause from peritoneal dialysis for at least two weeks, while it can be immediately continued after laparoscopy (Table 2). Overall, the laparoscopic approach still has an advantage in diagnosing this disease and due to the later performance of peritoneal dialysis should remain the first method in the treatment of catheter obstruction.

\section{Conclusion}

Mechanical complications connected with a peritoneal catheter and ovarian fimbriae are more often seen on the right side of the abdominal cavity and can be successfully solved with laparoscopy intervention. There is a need for more data from similar cases to evaluate the cause of this problem.

\section{Acknowledgements}

Not applicable.

\section{Authors' contributions}

IK conceiving study, writing the manuscript. JJ writing the manuscript, data acquisition and analyses, approval of the final version. IP approval of the final version. All authors read and approved the final manuscript.

\section{Funding}

None.

\section{Availability of data and materials}

The datasets used and/or analyzed during the current study are available from the corresponding author on reasonable request.

\section{Declarations}

Ethics approval and consent to participate

This study was approved by Clinical Hospital Merkur Ethics committee.

Consent for publication

All patients have given the consent for publication.

Competing interests

The authors declare that they have no competing interests.

\section{Author details}

${ }^{1}$ School of Medicine, University of Zagreb, Zagreb, Croatia. ${ }^{2}$ Clinical Hospital Merkur, Zagreb, Croatia.

Received: 15 August 2021 Accepted: 22 December 2021

Published online: 04 February 2022

\section{References}

1. Hill NR, Fatoba ST, Oke JL, et al. Global prevalence of chronic kidney disease - a systematic review and meta-analysis. PLOS ONE. 2016;11(7):e0158765.

2. Joachim E, Gardezi A, Chan MR, et al. Association of pre-transplant dialysis modality and post-transplant outcomes: a meta-analysis. Perit Dial Int. 2017;37(3):259-65.

3. Tullavardhana T, Aranurakkul P, Ungkitphaiboon W, et al. Surgical versus percutaneous techniques for peritoneal dialysis catheter placement: a meta-analysis of the outcomes. Ann Med Surg. 2016;10:11-8.

4. Figueiredo A, Goh BL, Jenkins S, et al. Clinical practice guidelines for peritoneal access. Perit Dial Int. 2010;30(4):424-9.

5. Strippoli GF, Tong A, Johnson D, et al. Antimicrobial agents to prevent peritonitis in peritoneal dialysis: a systematic review of randomized controlled trials. Am J Kidney Dis. 2004:44:591-603.

6. Peppelenbosch A, Willy $H$, van Kuijk M, et al. Peritoneal dialysis catheter placement technique and complications. NDT Plus. 2008;1 (Suppl 4):iv23-8.

7. Abouljoud MS, Cruz C, Dow RW, et al. Peritoneal dialysis catheter obstruction by a fallopian tube: a case report. Perit Dial Int. 1992;12:257-8.

8. Uchiyama K, Fujikawa K, Suga A, et al. Laparoscopic salvage of malfunctioning peritoneal dialysis catheters caused by ovarian fimbria: a case report. Hinyokika Kiyo. 2001;47:669-71.

9. Gudsoorkar PS, Penner T, Jassal SV, et al. The enigmatic fallopian tube: a more common cause of catheter malfunction than previously recognized. Perit Dial Int. 2016;36:459-61.

10. Klein Z, Magen E, Fishman A, et al. Laparoscopic salpingectomy: the definite treatment for peritoneal dialysis catheter outflow obstruction caused by oviductal fimbriae. J Laparoendosc Adv Surg Tech A. 2003;13:65-8.

11. Moreiras-Plaza M, Caceres-Alvarado N. Peritoneal dialysis catheter obstruction caused by Fallopian tube wrapping. Am J Kidney Dis. 2004;44:e28-30.

12. Čala Z, Soldo I, Perko Z, et al. Effective laparoscopic catheter insertion technique for peritoneal dialysis using specially designed trocar: 22 years multi-center retrospective study of 804 patients. Surg Sci. 2018;9:135-47.

13. Sakurada T, Kohatsu K, Yamada S, et al. Minilaparotomy for malfunctioning peritoneal dialysis catheter by nephrologists: experiences at two centers. Renal Replace Ther. 2020;6:14.

14. Abidin MR, Spector DA, Kittur DS. Peritoneal dialysis catheter outflow obstruction due to oviductal fimbriae: a case report. Am J Kidney Dis. 1990;16(3):256-8.

15. Amerling R, Maele DV, Spivak $H$, et al. Laparoscopic salvage of malfunctioning peritoneal catheters. Surg Endosc. 1997;11(3):249-52.

16. Kimmelstiel FM, Miller RE, Molinelli BM, et al. Laparoscopic management of peritoneal dialysis catheters. Surg Gynecol Obstet. 1993;176:565-70.

17. Owens LV, Brader AH. Laparoscopic salvage of Tenckhoff catheters. Surg Endosc. 1995;9:517-8.

18. Kittur DS, Gazaway PM, Abidin MR. Laparoscopic repositioning of malfunctioning peritoneal dialysis catheters. Surg Laparosc Endosc. 1991;1:179-82. 
19. Brandt CP, Ricanati ES. Use of laparoscopy in the management of malfunctioning peritoneal dialysis catheters. Adv Perit Dial. 1996;12:223-6.

20. Crabtree JH, Fishman A. Laparoscopic omentectomy for peritoneal dialysis catheter flow obstruction: a case report and review of the literature. Surg Laparosc Endosc Percutan tech. 1999;9(3):228-33.

21. Zakaria HM. Laparoscopic management of malfunctioning peritoneal dialysis catheters. Oman Med J. 2011;26(3):171-4.

22. Ogunc $G$, Tuncer M, Ogunc D, et al. Laparoscopic omental fixation technique versus open surgical placement of peritoneal dialysis catheters. Surg Endosc. 2003;17(11):1749-55.

23. Crabtree $\mathrm{JH}$, Bruchette RJ. Effective use of laparoscopy for long-term peritoneal dialysis access. Am J Surg. 2009;198(1):135-41.

24. Aldohayan A, Alshomer F, Al-Naami M, et al. Laparoscopic oviductal fimbrioplasty for peritoneal dialysis catheter outflow obstruction caused by ovarian fimbriae. Saudi J Laparosc. 2016;1:20-2.

25. Janež J, Pajek J, Knap B. A rare cause of peritoneal dialysis catheter obstruction with fallopian tube and fimbriae. Indian J Perit Dial. 2017;33:30-2.

26. Macallister RJ, Morgan SH. Fallopian tube capture of chronic peritoneal dialysis catheters. Perit Dial Int. 1993;13(1):74-6.

27. Harrison NA, Howell GP, Rainford DJ. Fallopian tube capture of a peritoneal dialysis catheter. Nephron. 1988;50(3):258.

28. Sinha R, Dastidar A. Obstruction of a peritoneal dialysis catheter by an ovarian fimbria in a 2-year-old girl. Am J Kidney Dis. 2011;57(2):356-7.

29. Borghol M, Alrabeeah A. Entrapment of the appendix and the fallopian tube in peritoneal dialysis catheters in two children. J Pediatr Surg. 1996;31(3):427-9.

30. Cuxart M, Domingo J, Cufi M, Picazo M, Sans R. Disfunción del catéter de diálisis peritoneal por atrapamiento de la trompa de Falopio. Nefrologia. 2019;39(5):556-7.

31. Gudsoorkar PS, Penner T, Jassal SV, Bargman JM. The enigmatic fallopian tube: a more common cause of catheter malfunction than previously recognized. Perit Dial Int. 2016;36(4):459-61.

32. $\mathrm{Hu}$ J, Liu Z, Liu J, Zhang H. Reducing the occurrence rate of catheter dysfunction in peritoneal dialysis: a single-center experience about CQI. Ren Fail. 2018:40:628-33.

33. Zhang L, Liu J, Shu J, et al. Low-site peritoneal catheter implantation decreases tip migration and omental wrapping. Perit Dial Int. 2011;31:202-4.

\section{Publisher's Note}

Springer Nature remains neutral with regard to jurisdictional claims in published maps and institutional affiliations.

Ready to submit your research? Choose BMC and benefit from:

- fast, convenient online submission

- thorough peer review by experienced researchers in your field

- rapid publication on acceptance

- support for research data, including large and complex data types

- gold Open Access which fosters wider collaboration and increased citations

- maximum visibility for your research: over 100M website views per year

At BMC, research is always in progress.

Learn more biomedcentral.com/submissions 